\title{
Comparison Between the COVID-19 Epidemic and Global Credit Crisis in 2008
}

\author{
Wu Sirui \\ Harbin No.3 High School International Department, Harbin, China, 150000 \\ Corresponding author. Email: $3021436482 @ q q . c o m$
}

\begin{abstract}
The current global epidemic of Corona Virus Disease 2019 is spreading. With the increasing uncertainty of the severity and duration of the pandemic, economic and social stagnation, the break of global industrial chain, and the economic and food security of countries are affected, which bring market panic. So far, it has spread rapidly and caused a large number of casualties. The impact on the affected countries, especially the most vulnerable social sectors, is undoubtedly the biggest public health emergency of this year. This paper discusses how the COVID-19 epidemic impact on the economy from an economic perspective.
\end{abstract}

Keywords: COVID-19, subprime mortgage crisis, globalization, health, crisis

\section{INTRODUCTION}

On 11 March, the World Health Organization (WHO) characterized the new coronavirus (COVID-19) epidemic as a global pandemic. Twelve years later, the global economic was once again hit hard. [1]COVID-19 global pandemic and the sharp drop in oil prices have exacerbated the deep political, social, economic and security crises. Global economy has been decimated by slow growth and rising inequality far beyond imagination.

The epidemic continues to spread rapidly across the United States with more than 2.9 million confirmed cases. Under the influence of the oil crisis and the epidemic, the U.S. stock market continued to fall, while global stock markets were falling.[2] As the largest financial market, the United States economy is directly affected by the turbulence, fell into a recession in the first half of this year. Whether a long-term recession can be avoided in the future depends on the development of the epidemic and timely appropriate stimulus measures.

University of California, Berkeley law professor Frank Partnoy recently warned that the outbreak of the epidemic may cause a large number of subprime mortgage crises, again triggering a financial crisis similar to 2008, leading to a large number of bank failures.[3]

The financial crisis began with the "subprime mortgage crisis" in the United States in August 2007, and then broke out into a global credit crisis in September 2008.[4] The crisis was the result of a combination of factors, including loose monetary policy, deregulation, excessive bank risk-taking and a credit or debt surge between 2002 and 2007. The epidemic is a sudden global health crisis. Under the impact of the epidemic, many industries have been shut down in stages, resulting in the stagnation of production and business activities, including transportation, wholesale and retail, tourism, accommodation, catering, entertainment, agriculture, forestry, animal husbandry and other industries. Although both have a serious impact on the global economy, the economic impact of the new coronary pneumonia and the subprime crisis are still different.

\section{ANALYSIS}

\subsection{Two Conduction Paths Are Different}

The crisis began with the real economy, and the 2008 subprime crisis was triggered mainly by financial markets. This is a real economic crisis and a public health crisis. The transmission path of the subprime mortgage crisis in 2008 is from the financial system to the real economy, and the transmission path of this epidemic is from the real economy to the financial system. Quantitative easing can prevent the financial crisis from erupting, but for the real economy, its effect must be indirect and lagging. The recovery of the global 
real economy continues to depend on the time when the epidemic is fully under control.

Monetary and fiscal stimulus is difficult to address directly the real economy's problems, which will force stimulus policies not to exit in the short term, or even passively add. In this context, the future liquidity that supports capital markets must be long-term positive. Although the epidemic did not directly impact the stability of global financial liquidity as the 2008 financial crisis, the impact on economic recovery caused by business shutdown and increased unemployment can not be ignored.
In general, in the context of comprehensive quantitative easing by governments, with the disruption of the transmission path of the real economic shock caused by the epidemic to the systemic financial crisis, the probability of a large systematic downward trend in the stock market without the emergence of new black swans is not high. The stratification of the market in different stages of structure will be more extreme due to the synchronization of the recovery of the global real economy and industrial chain. Policy makers should maintain the economic health of the region with loose macroeconomic policies, which is essential for sustainable development.

\section{UNEMPLOYED PERMANENT JOB LOSERS}

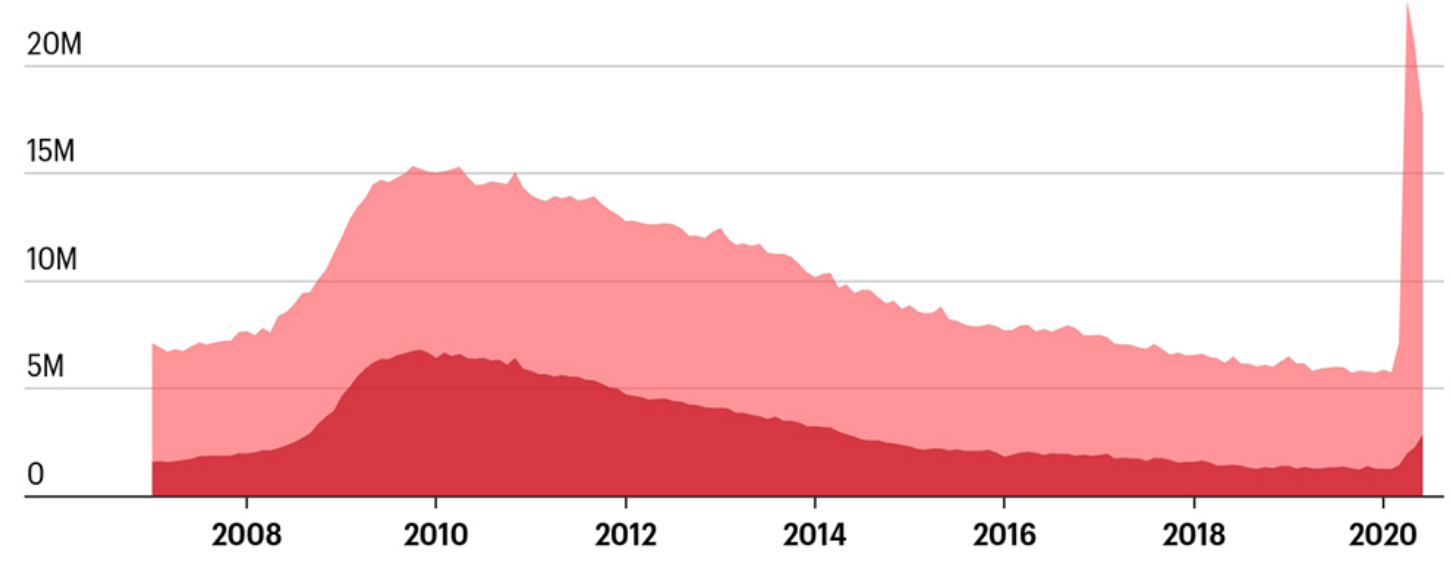

SEASONALLY ADJUSTED

CHART: LANCE LAMBERT • SOURCE: U.S. BUREAU OF LABOR STATISTICS

\section{FORTUNE}

Figure 1 Data of American unemployment[5]

\subsection{Data Display}

The 2008 subprime mortgage crisis is both a derivative financial crisis and a complex crisis, but it is relatively mild in nature only in the economic and financial sectors. This pandemic crisis not only directly threatens the safety of property, but also threatens people's lives. This time the risk is irreversible, the losses caused by the subprime crisis can be repaired, the epidemic has kept consumers confined to their homes, and the role of monetary policy regulation has been greatly reduced.

In the past, as long as the panic and turbulence in the financial market were controlled, the first stage of financial deleveraging could even be temporarily stabilized. However, during this period, it may have to be seen that this epidemic has a certain preventive and control effect in order to completely stabilize the first stage. The spread of the current epidemic in South Korea, Japan has been initially controlled, while Europe and the United States are still not good. The panic and volatility of financial markets are beyond words. If this countries are eager to remove restrictions and resume production, the economic impact may be more serious and long-term.

Before the subprime crisis erupted in 2008, the market had been superstitious that house prices would not fall, thus underestimating the risk of default on subprime loans and their derivatives. The mainstream view is that economic integration and diversification can reduce risks, and certain solutions for securitization and the spread of financial products around the world can be provided. The problems in the US subprime mortgage market in mid-2007 developed into a systemic crisis only a year later, which not only dragged down the credit markets of all developed countries, but also had a great negative impact on the real economy. During the financial crises of 2007 and 2008, secured loan vouchers (CLO) were risk-free and there was no need to worry that companies applying for these loans would default at the same time, but now the new coronavirus epidemic has caused many companies to have serious economic difficulties, which may cause a large number of 
enterprises to default at the same time, and the current secured loan certificate (CLO) is at serious risk.

PMI has fallen under 50 , signaling a contracting manufacturing sector.

$-\mathrm{PMI}$

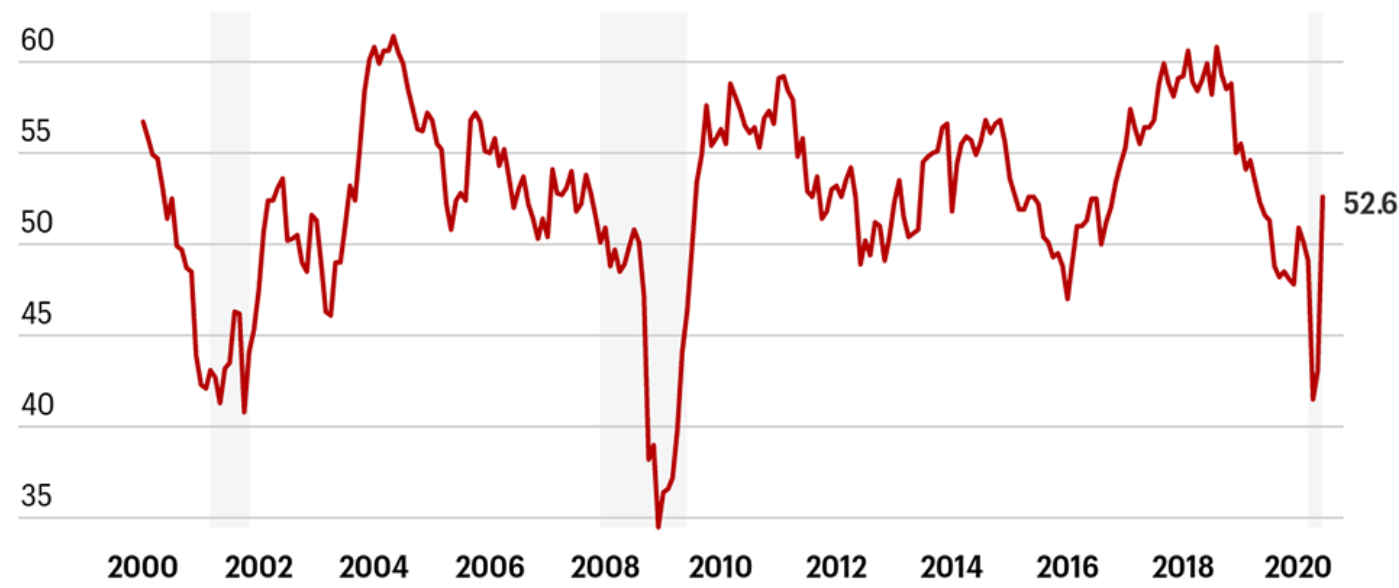

DATA THROUGH JUNE 2020. HIGHLIGHTED AREA NOTES A RECESSION.

CHART: LANCE LAMBERT • SOURCE: THE INSTITUTE FOR SUPPLY MANAGEMENT

Figure 2 Manufacturing Purchasing Managers Index[6]

\subsection{The Empirical Means of Coping Are Different}

In the face of the dilemma of crisis, human beings have made considerable progress in both theory and practice, and have accumulated rich experience, which enables countries to formulate correct policy measures to effectively hedge and control risks when the crisis comes.

Twelve years ago, the Fed took a series of extraordinary measures of keeping its benchmark short-term interest rate at its lowest level near zero and for seven full years. Over the years, the Fed has continued to purchase billions of dollars in U.S. Treasury bonds and mortgage bonds, reducing long-term borrowing rates. Bond purchases also reduce interest rates on bonds and other fixed income investments. As a result, stock demand increases as investors seek higher returns than low-yield bonds. After 2008, the Fed's move pushed U.S. stocks into an 11-year bull market. Most of the current monetary policy launched by the Federal Reserve is the restart of monetary policy tools in the subprime mortgage crisis in 2008 , but there are differences in the size and content of monetary policy tools.

Unlike the financial crisis caused by the subprime mortgage crisis in 2008, The epidemic crisis stopped the economic recovery, and the Fed introduced unprecedented measures to provide liquidity to all sectors of the economy that are in a state of "full fire ”. The Federal Reserve recently reduced interest rates to close to zero and expanded its unlimited easing policy. It also uses student loans, credit card loans, and U.S. government-guaranteed loans as collateral to provide loans to small businesses and purchase large corporate bonds to provide them with up to four years Bridge loan. Also, the Fed will provide financial support to local governments by launching three new lending instruments to revive the term-asset mortgage-bond facility (TALF) during the 2008 global financial crisis to support consumer and corporate credit markets.

\section{CONCLUSION}

The COVID-19 epidemic crisis and the subprime mortgage crisis need different solutions in different times. The similarity lies in the economic impact, but both are fundamentally different. From the starting point of the crisis, the 2008 subprime mortgage crisis originated in the United States economic growth slowdown and interest rate rising in the background of the financial market shock. The collapse of the subprime mortgage market and the loose monetary environment let poor credit qualifications of residents to leverage, which magnified the risk. With the continued downturn in the real estate market and the deepening of the credit crisis, various macroeconomic indicators reflect the economic recession: declining employment rates, a rapid decline in consumer confidence, a sharp decline in household spending, and a decline in corporate equipment spending, affecting the global economic market. The financial turmoil facing the United States this time is due to the global spread of the COVID-19 epidemic and the damage to the global industrial chain, which will cause global currency liquidity no longer to grow. 
In countries that are not directly affected by the epidemic, this situation will gradually emerge. The economic environment is uncertain and trade tensions are unresolved. As capital inflows decline, more diversified economies will face the limits of foreign exchange to domestic demand growth, which will create severe macro imbalances and the possibility of inflation, and the rise in leverage and the expansion of asset bubbles will have a more direct impact on the real economy.

Of course, the epidemic crisis may not only become a huge health crisis, but also a crisis of globalization and global governance, and the problems exposed by the crisis are even more worthy of consideration. The scale and scope of globalization have made the world more interdependent than ever and connectivity poses a huge (but often hidden) risk of disaster. This is because connectivity increases what statisticians call the "fat tail effect ", the likelihood of extreme events that themselves cannot be quantified, such as financial crises, nuclear holocausts, hostile artificial intelligence, global warming, destructive biotechnology, and epidemics.

From the devastating impact of the 2008 financial crisis on the world economy to the impact of today's COVID-19 epidemic crisis on countries, one cannot help thinking about the systemic and paralysing consequences of an integrated global economy. This epidemic has forced new demands to emerge. People are also considering how to prevent and control an infectious disease pandemic and create functional redundancy in complex systems including finance, value chain, food supply and public health to prevent infectious diseases. The hub does not become a bottleneck and ensures that a single failure does not cause the system to crash. At present, the development of the epidemic situation in the West, as well as the contradictory struggle and complex situation around the epidemic situation are still continuing, but the prospect of the epidemic being finally controlled can be expected.

After the epidemic is under control and the disaster is restored, the world economy will face a new problem-besides returning to the "fundamental", that is how to solve the "sequelae" policy. At the same time, there will also be the problem of solving internal problems and power changes, as well as the game problem of transfer costs between countries, which will lead to the deepening and intensification of economic and political contradictions between countries, and will also make the game possible. It is more complicated between countries.

\section{ACKNOWLEDGMENT}

The author thanks all the teachers for their help and support, completed the topic selection, data sorting, thinking sorting and language expression, and also thanked family and classmates for their support when encountering difficulties.

\section{REFERENCES}

[1] Coronavirus disease (COVID-19) pandemic. World Health Organization.2019.

https://www.who.int/zh/emergencies/diseases/nove 1-coronavirus-2019

[2] Epidemic: The three major global economic recession factors behind the plunge in oil prices. BBC.NEWS. 2020.3.10.

https://www.bbc.com/zhongwen/simp/business-518 14518

[3] The epidemic in the U.S. may cause a subprime mortgage crisis and trigger another financial turmoil. OLIAN. 2020.6.20. http://www.oliannews.com/gj/2020/06-21/331949.s html

[4] From Subprime Mortgage Crisis to Financial Crisis: Causes and Effects. School of Economics Shandong University. 2008.11.10. https://www.econ.sdu.edu.cn/info/1346/24463.htm.

[5] Lance Lambert. U.S. Bureau of Labor Statistics. 2020.6. http://www.bls.gov/

[6] Lance Lambert. U.S. Bureau of Labor Statistics. 2020.6. http://www.bls.gov/ 